\title{
Advanced Application of Electrospun Polycaprolactone Fibers for Seed Germination Activity
}

\author{
Fatirah Fadil $\left(\mathbb{D},{ }^{1}\right.$ Nor Dalila Nor Affandi $\left(\mathbb{D},{ }^{1}\right.$ Nur Aqilah Ibrahim $\left(\mathbb{D},{ }^{1}\right.$ \\ Mohd Iqbal Misnon $\mathbb{D}^{1}$, Ahmad Mukifza Harun $\mathbb{D}^{2}, 2$ and Mohammad Khursheed Alam $\mathbb{D}^{3,4}$ \\ ${ }^{1}$ Faculty of Applied Sciences, Universiti Teknologi MARA, Shah Alam, 40450 Selangor, Malaysia \\ ${ }^{2}$ University Malaysia Sabah, Kota Kinabalu, 88400 Sabah, Malaysia \\ ${ }^{3}$ Jouf University, Sakaka 72721, Saudi Arabia \\ ${ }^{4}$ Department of Dental Research Cell, Saveetha Dental College and Hospitals, Saveetha Institute of Medical and Technical Sciences, \\ Chennai, India
}

Correspondence should be addressed to Nor Dalila Nor Affandi; dalila@uitm.edu.my, Ahmad Mukifza Harun; mukifza@ums.edu.my, and Mohammad Khursheed Alam; dralam@gmail.com

Received 23 April 2021; Revised 1 September 2021; Accepted 21 September 2021; Published 7 October 2021

Academic Editor: Wen Li

Copyright (C) 2021 Fatirah Fadil et al. This is an open access article distributed under the Creative Commons Attribution License, which permits unrestricted use, distribution, and reproduction in any medium, provided the original work is properly cited.

\begin{abstract}
The increasing intensity of coronavirus (COVID-19) spreading emphasizes the significant development in home food production to reduce the incoming socioeconomic impact from soaring food prices, supply chain fragility, and severe economic crisis. This preliminary study was initiated to demonstrate the possibility of using electrospun fibers as a potential substrate in the application of seed germination activity. The drive of this preliminary study was to integrate the electrospun nanofiber-based material in exploring the current surge in home food production via seed germination in order to introduce cheap source of food without being distracted by the pandemic impact in general. Mung bean (Vigna radiata L. Wilczek) was chosen as it is easy and fast to sprout. Four samples of poly ( $\varepsilon$-caprolactone)- (PCL-) based fibers were prepared by means of electrospinning technique, with the optimized flow rate between 0.05 and $0.20 \mathrm{ml} / \mathrm{min}$ at a fixed distance of $10 \mathrm{~cm}$ needle tip to collector. Mung bean seeds were allowed to germinate on the fabricated electrospun PCL fibers for 96 hours. Our observations include germination percentage, seedling weight, radicle length, and plumule growth. The highest radicle length and plumule length of seedlings were $27.8 \mathrm{~mm}$ and $6.7 \mathrm{~mm}$, respectively. There were no inhibitory effects on seed germination and minimal structural fragmentation of smaller diameter electrospun fibers as revealed by FESEM. These results show that the seeds were able to germinate on electrospun PCL fiber substrate, owing to the properties of high surface area and excellent fluid water uptake of PCL fibers.
\end{abstract}

\section{Introduction}

As of December 2019, the entire world has been shocked by the outbreak of the novel coronavirus (COVID-19) pandemic which has delivered the fastest, deepest global economic crisis in history [1]. The occurrence of the COVID19 has affected people in the world, as they lost their income and the limited access to a nutritious diet of whole grains, lean meats, and fresh vegetables and fruits [2]. In addition, most countries have encountered a huge issue of the food supply shortage as most nations enforce the COVID-19 lockdown. Dietary choice limitation and soaring food prices pose significant barriers for many people who are trying to balance good nutrition with affordability amidst the current pandemic [3]. Mung bean (Vigna radiata L. Wilczek), a grain legume crop that belongs to the Fabaceae botanical family, is one of the easiest and fastest to sprout. They are cheap, abundant, and reliable, offer roughly $20.97-31.32 \%$ of protein, and have been widely consumed as a meatalternative protein source in most developing and underdeveloped countries $[4,5]$. They are considered as nutrientrich foods as they are high in dietary fibers, antioxidants, and resistant starch and low in calories [6,7]. Mung bean has been extensively cultivated and is often used as an 
ingredient in daily meals since ancient times especially in China, India, and Southeast Asia. These sprouts could be served in many ways, such as fried and boiled, and could also be enjoyed raw. It is reported that the nutritional value per $100 \mathrm{~g}$ of mung bean sprout contains $7 \mathrm{~g}$ protein, $18 \mathrm{~g}$ carbohydrate, $24 \mathrm{~g}$ fat, $0.026 \mathrm{~g}$ sodium, $0.06 \mathrm{~g}$ potassium, $0.02 \mathrm{~g}$ iron, $0.029 \mathrm{~g}$ calcium, 103.5 calories of energy, and other important vitamins [8].

According to Faisal et al., seed germination and growth of mung beans were found to significantly depend on the relative humidity of the air [9]. Other important variable factors for mung bean germination include optimum temperature, oxygen, and clean water. In addition, it also requires suitable substrates to promote germination and seedling growth [10]. In this preliminary work, the novel application was to imply the electrospun fibers fabricated from electrospinning technique, as a potential substrate for mung bean seed germination, which was explored for the first time. Electrospinning is a facile applied technique, which uses an electrical potential to convert droplets of a polymer solution into fibers of nanometers in diameter that can be collected in the form of a fibrous mat $[11,12]$. These fibrous mats consist of ejected polymer fibers, which are deposited on a grounded collector in a random (nonwoven) arrangement. Electrospun fibers with remarkable properties, such as high specific surface area, flexibility, variety of morphology, surface roughness, superior directional strength, excellent pore interconnectivity, and ease of functionalization, have been extensively employed in diverse applications; however, it was limited to filtration [13-15], scaffolds [16-18], and biosensors [19]. Despite the exponentially growing literature on electrospinning for diverse applications, the studies into the functional application of electrospun fibers towards plant growth are scarcely reported [20,21]. As of this writing, there are few articles that reported on the application of electrospun polycaprolactone (PCL) nanofibers as a substrate for an artificial system of soilless medium in seed germination. The selection of PCL in this research was due to its biodegradable and biocompatible properties, which are reported as an ideal polymer for agricultural mulch films, controlled or slow release agrochemical, and also attributed to a suitable super absorbent material [22-24]. This present study was carried out to evaluate the response of mung bean seed early growth, seed viability, germination activity, morphological changes, fluid water uptake, and water vapor permeability properties of PCL fibers with the aim of developing electrospun fiber material as a substrate for germinating seeds.

\section{Materials and Methods}

2.1. Electrospinning Process. Poly ( $\varepsilon$-caprolactone) (PCL) granules with the molecular weight average $80,000 \mathrm{~g} / \mathrm{mol}$ (Mw) were dissolved in dichloromethane (DCM), anhydrous, $\geq 99.8 \%$ solution and stirred 24 hours at room temperature. The prepared PCL solution of $10 \mathrm{wt} \%$ was then loaded into a plastic syringe equipped with a $0.4 \mathrm{~mm}$ internal diameter of a blunt needle, with a needle-collector distance of $10 \mathrm{~cm}$, attached to a high-voltage power supply and the ground connected collector. A high-voltage value of $15 \mathrm{kV}$ was applied to an end of the needle to create voltage differences between the needle and a ground collector. A syringe pump was used to deliver the polymer solution from a syringe to the needle at a distinctive flow rate of $0.05,0.10$, 0.15 , and $0.20 \mathrm{ml} / \mathrm{min}$. All the electrospinning processes were performed using a custom-built electrospinning reactor in a dedicated cabin, outfitted with a control operating panel, to protect the user from a number of risks. All four samples of electrospun PCL fibers were collected and stored in a desiccator until further evaluation.

2.2. Fiber Characterization. The surface morphology of the fabricated electrospun fibers was characterized using the Field Emission Scanning Electron Microscope (FESEM) (Carl Zeiss, Supra 40vp). Electrospun fiber specimens were gold coated using a sputter coater (Sputter Coater 108; Cressington Scientific Instruments) to obtain an electrically conductive surface, before being subjected to the FESEM analysis. The average diameter and standard deviation (SD) of the electrospun fibers were determined. The fiber diameters of 50 points were taken randomly and measured using an image analysis software (ImageJ, National Institutes of Health, USA).

For the properties of fluid uptake ability, a section of electrospun fiber mat for each of the fiber specimen was cut and dried at room temperature. It was then immersed into a beaker filled with distilled water for 30 minutes. The wet electrospun fiber mat specimens were taken out and placed on a clean absorbing paper for 30 seconds, and the measurements of their final weight were recorded. The fluid uptake ability (FUA) of the electrospun fibers was calculated as a percentage of water loss per unit weight:

$$
\operatorname{FUA}(\%)=\frac{W_{\mathrm{s}}-W_{\mathrm{d}}}{W_{\mathrm{s}}} \times 100 \%,
$$

where $W_{s}$ is the wet weight of the electrospun fibers and $W_{d}$ is the dry weight of the electrospun fibers $[25,26]$.

The determination of water vapor permeability properties of electrospun fibers was performed using the Upright Cup Method principle using the SDL Atlas M21 Water Vapor Permeability Tester, as per instructed in the ASTM E96 in Textile Fabric Testing Standard. The performance of water vapor transmission of the electrospun fibers was evaluated in the following approach. Containers filled with $3 \mathrm{ml}$ distilled water were covered with the electrospun fiber mat of the four samples, respectively. The covered containers were placed in an airtight environment chamber. The weight of the containers was measured once every hour over a period of 8 hours. The difference of the measured weight was divided by the cross-sectional area of the container. The water vapor transmission rate (WVTR) was calculated as

$$
\mathrm{WVTR}=\frac{\Delta W}{\Delta t \cdot A} \mathrm{mg} \mathrm{h}^{-1} \mathrm{~cm}^{-2},
$$

where $\Delta W / \Delta t$ is the amount of water loss (milligram) per unit time (hour) of moisture transfer and $A$ is the evaporation exposure area in $\mathrm{cm}^{2}[27,28]$. 


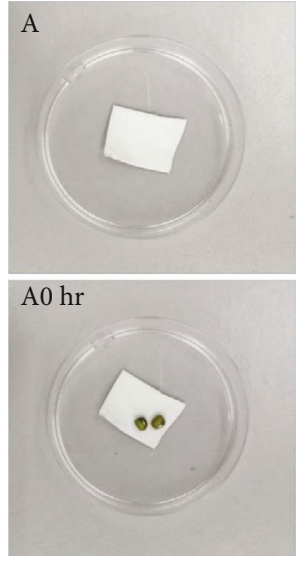

(a)
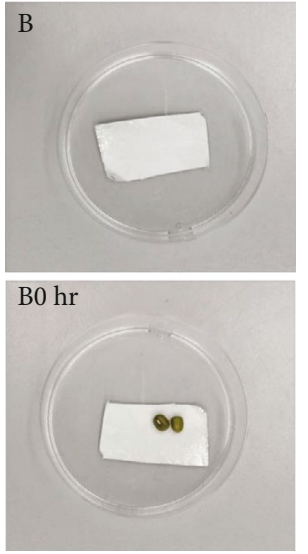

(b)
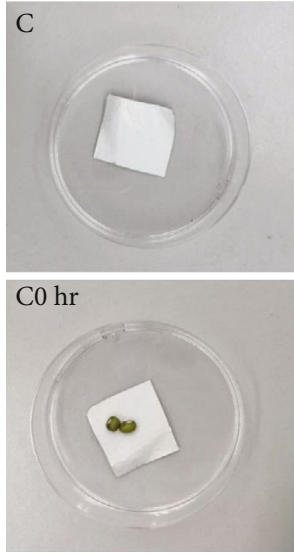

(c)
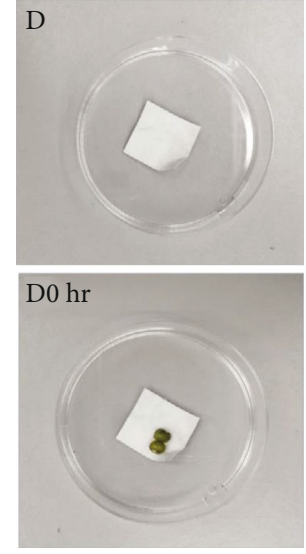

(d)

Figure 1: (a-d) The optical photographs of as-synthesized electrospun PCL fiber membrane at distinctive flow rates of $0.05,0.10,0.15$, and 0.20 without and with seed placement at 0 hours, respectively.

2.3. Seed Germination Activity. Fresh mung bean seeds used in the experiment were purchased from the local market. Approximately uniform mung beans based on weight were selected for the experiment. Analytical grade chemicals and distilled water were used in the study. The experiment was conducted using electrospun fibers as a germination substrate for the growth of mung bean seeds as shown in Figures 1(a)-1(d). The seeds were placed into each of the moistened electrospun fibers in four individual Petri dishes and kept for germination process in a dark place at ambient temperature $\left(27^{\circ} \mathrm{C}\right)$ [10]. One to $3 \mathrm{ml}$ of distilled water was added in the interval of 24 hours to keep the electrospun fiber substrate moistened throughout the process of seed germination. The status of seed germination was observed between 0 hours and 96 hours. The observations include seed coat rapture, radicle length, plumule growth, and percent germination. The percentage of germination was calculated by the following formula:

$$
V=\frac{\mathrm{NSp}}{\mathrm{NSd}} \times 100 \%
$$

where $V$ is the viability level, NSp is the number of sprouting seed, and NSd is the number of seeds [8]. The weight of the seeds was determined gravimetrically every $24 \mathrm{~h}$ for $96 \mathrm{~h}$ after unbound moisture had been removed from the seed surface with a laboratory wipe.

\section{Results and Discussion}

3.1. Seedling Growth. This work describes the results of study undertaken to evaluate the role of the electrospun fiber substrate to support the germination of seeds. In this study, the response of germinating mung bean seeds on electrospun PCL fibers was assessed. The observation shows that a hundred percent of mung bean seeds were successfully germinated on each of the germinating Petri dishes under certain controlled conditions. Seed germination parameters of mung bean seeds are presented in Figure 2.
One of the seedling growth parameters was indicated by an increase in seedling weight as compared to the weight of dry seeds. The increment of seedling weight was recorded over $100 \%$ in the first 24 hours of the germinating period (see Figure 2(a)). It was observed that the size of the seeds was increased to triple due to the water imbibition process, where the water molecule penetrates the seed coat and began to soften the hard and dry tissues inside. The water uptake had initiated the seed to swell up, which then resulted in the rupture of the seed coat between 0 hours and 24 hours of the germinating period. The color of mung beans was observed in light yellow as the seed coats were removed. Similar to other types of seeds, mung bean has a small lifesupport system as the sources of initial nutrition for their early growth [28]. The growth of quiescent embryos within the seed began as a consequence of the triphasic process of water imbibition in the seeds that finally shedded off the seed coat, and the radicle emergence started between 24 hours and 48 hours during the germination period. Hydrated enzymes in the mung bean seed were activated, and the seed increased its metabolic activities to produce energy for the growth process [29]. In addition, the water imbibition increased the turgor pressure within the cell walls of the seed and continually expanded during the growth [30]. The imbibition of the seed coats then resulted in the emergence of the plumule, and the cotyledons unfolded after 72 hours of the germinating period. Then, it was observed that the development of radicle and plumule started to elongate upon the indirect pathways to light [31]. The color of cotyledons changed from light yellowish to green as they were exposed to light. The measurement of the radicle length and plumule growth at various time points is presented in Figures 2(a) and 2(b). In this present result, the increase in mass of mung bean seedlings was attributed to a faster water uptake, as noted by Krawiec et al. $[32,33]$. These results are in line with Akhalkatsi and Lösch who observed that any deficiency in water uptake induced to delay the initiation of the germination process [34]. In this study, it was revealed that the growing mung bean seedlings were ready to be replanted outdoors, 


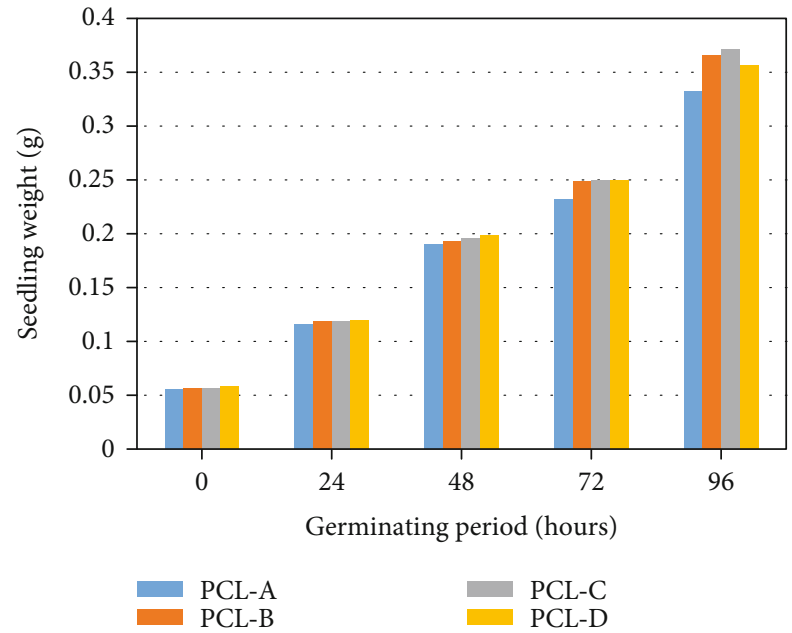

(a)

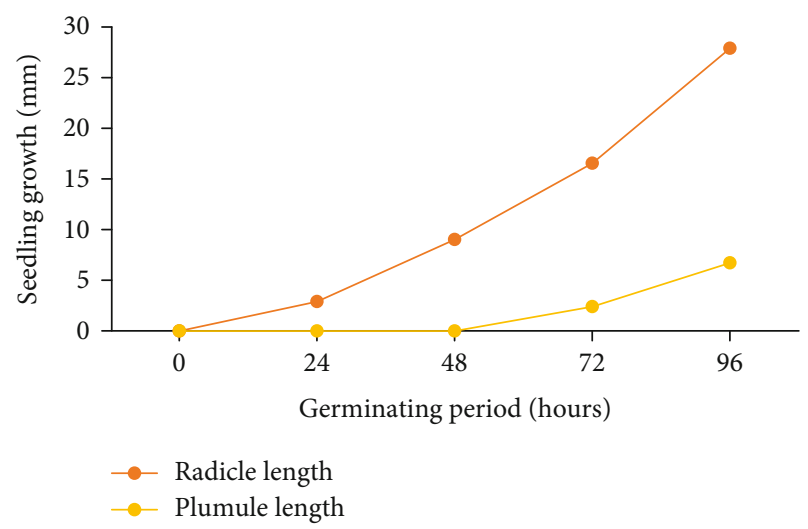

(b)

FIGURE 2: (a) Bar graph of seedling weight versus germinating period. (b) Linear graph of seedling growth versus germinating period.
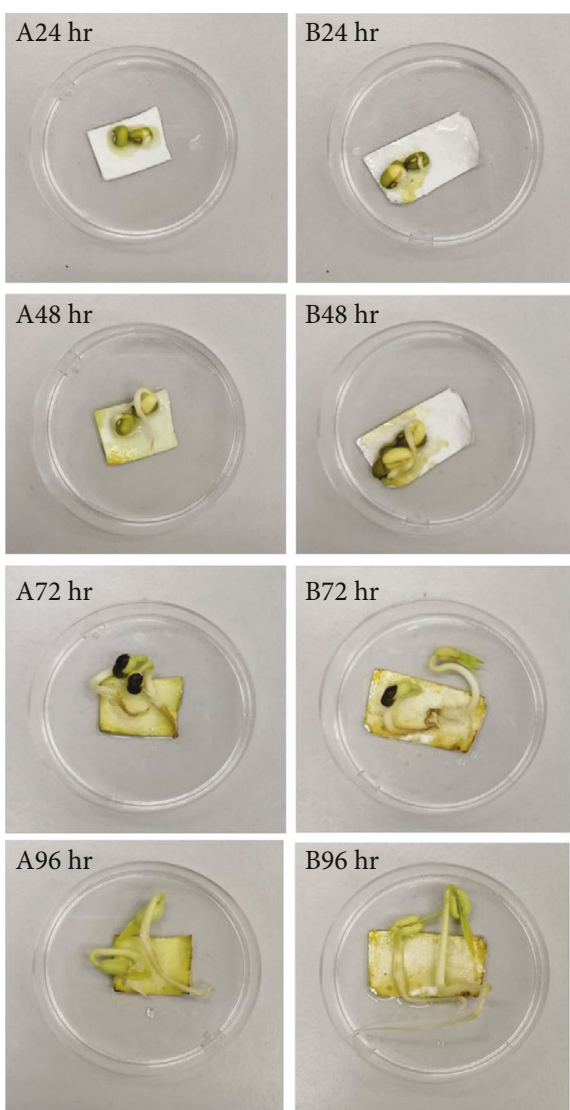
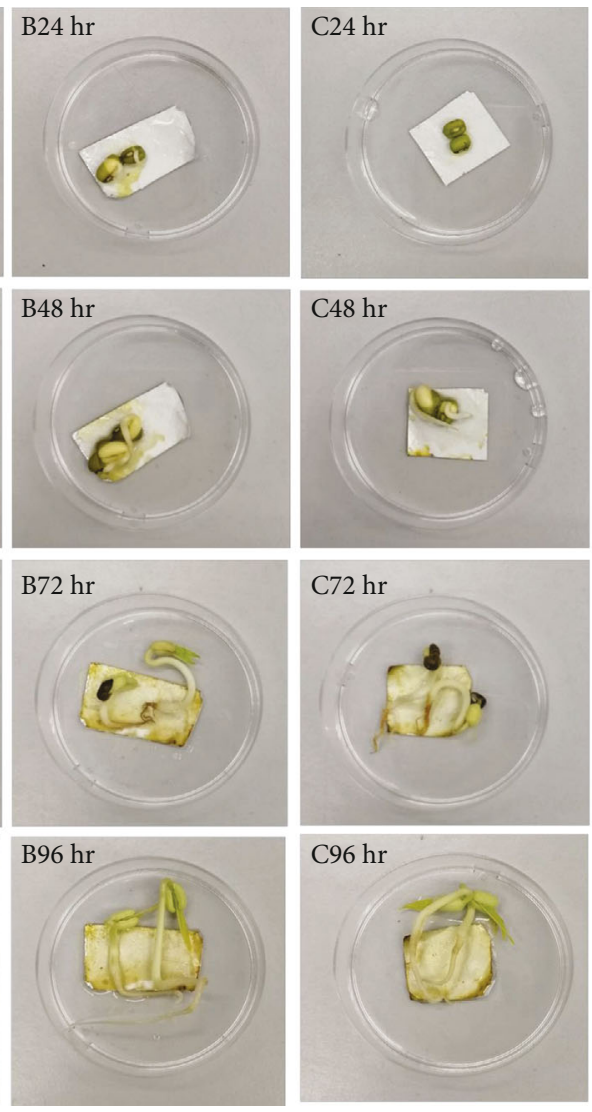

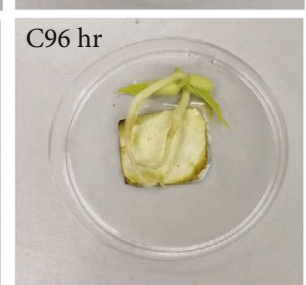

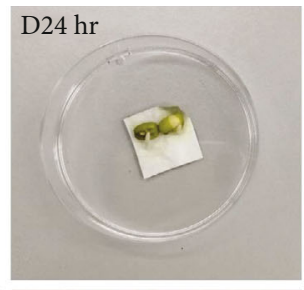
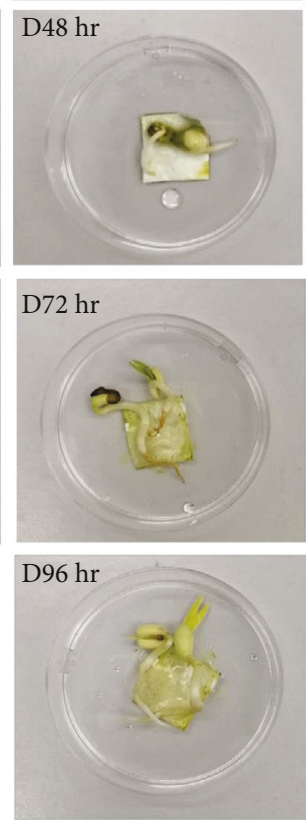

Figure 3: The optical photographs of seed germination on electrospun PCL fibers within 24, 48, 72, and 96 hours, respectively.

into the soil medium after 96 hours of germination period. Figure 3 depicts the optical photographs of mung bean seed germination on electrospun PCL fibers within 24- to 96hour period.

3.2. Morphological Changes of PCL Fibers. The changes on the morphological studies of PCL fiber structures before and after the germination of seeds are shown in Figures 4 and 5, respectively. From the FESEM images, the nonwoven fibers are in the nonuniform diameter size. The formation of these nonuniform fibers was probably due to the high volatility of solvent (dichloromethane) used to dissolve the PCL. Due to the low boiling point of dichloromethane (DCM) (approximately at $40^{\circ} \mathrm{C}$ ), the DCM was expected to evaporate faster at room temperature, which resulted in the nonuniform PCL fibers as well as pores on fiber structures. 


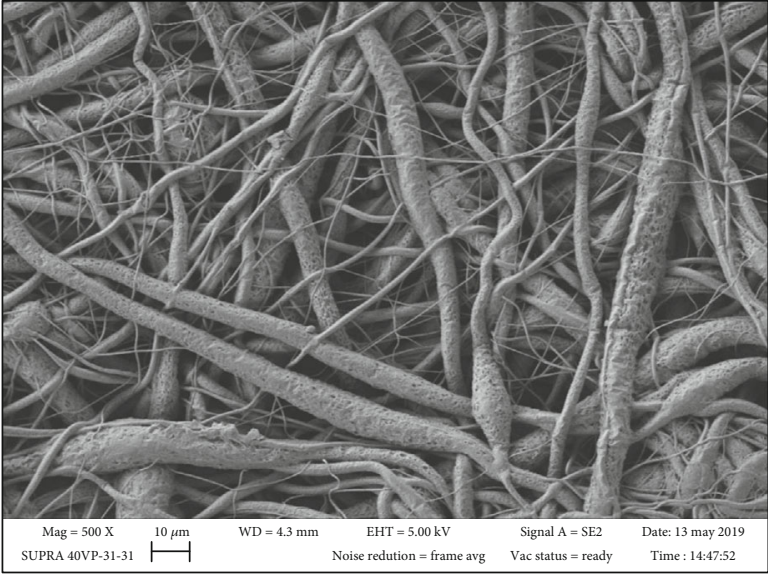

(a)

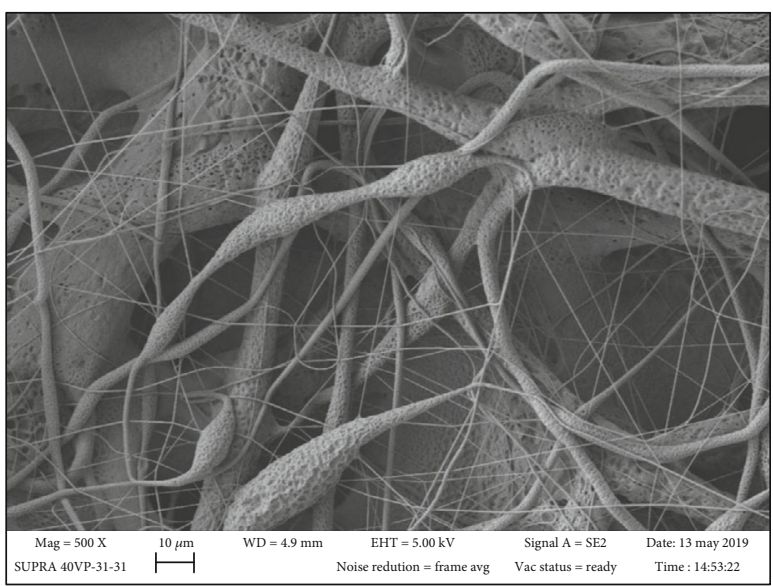

(c)

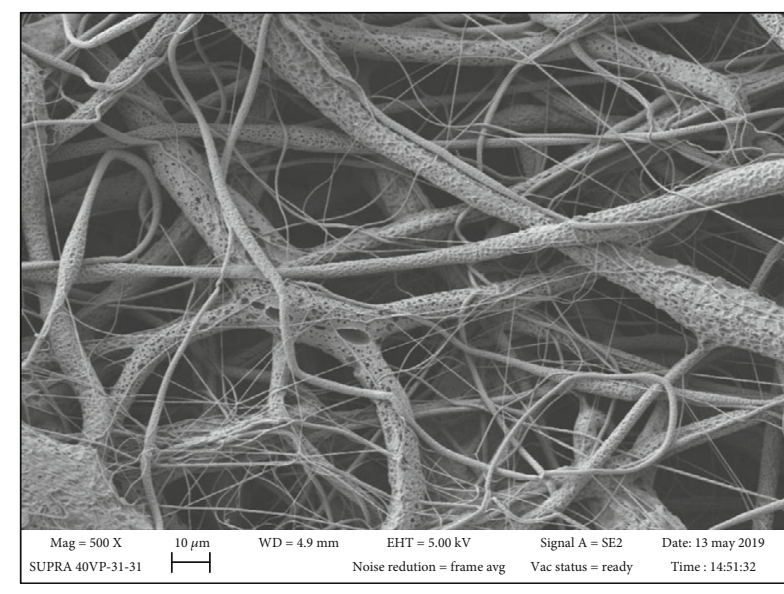

(b)

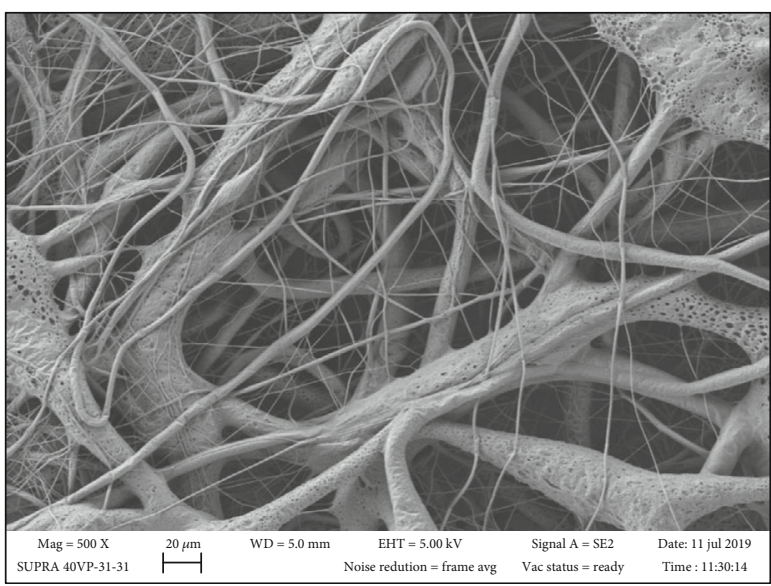

(d)

FIgure 4: FESEM of electrospun PCL fibers at the flow rates of (a) 0.05 , (b) 0.10 , (c) 0.15 , and (d) $0.20 \mathrm{ml} / \mathrm{min}$.

The average fiber diameter decreased from $3.807 \pm 2.97 \mu \mathrm{m}$ to $2.95 \pm 5.28 \mu \mathrm{m}$ as the flow rate increased from $0.05 \mathrm{ml} / \mathrm{min}$ to $0.2 \mathrm{ml} / \mathrm{min}$. The decrease in fiber diameter was most likely caused by an unstable polymeric jet at a high flow rate, resulting in nonuniform fibers with a combination of fine fibers. The details of the fiber diameter distributions and fiber thickness properties of as-synthesized PCL fibers were reported in our previous works $[35,36]$. For spent electrospun PCL fibers, there are no significant changes in the fiber diameter recorded upon the seed germination process. The fiber structures with larger diameters remained intact; however, a minimal structural breakage of ultrathin fibers was observed. The phenomenon is possibly due to the slight degradation of the PCL fibers in wet conditions. Poly ( $\varepsilon$-caprolactone) (PCL) is one of the synthetic biodegradable polymers with considerable degradation in aqueous media. In the study, the PCL fibers were moistened to allow the germination of the seed. This has resulted in fiber fragmentation as observed in Figures 5(e)-5(h). Other studies have also observed the fragmentation of the PCL fibers after the fibers were immersed in water $[37,38]$. On the contrary, the higher number of entanglements between fibers sustained the structural integrity among the larger fibers $[39,40]$.
This study shows that there are no inhibitory effects on the mung bean seedling growth that were observed during the germinating period. The interconnected pores within electrospun PCL fibers show the ability to absorb and store water molecules due to the higher capillary forces from the fiber structures [41] to keep the moisture content and provide an excellent germinating substrate for the seeds to grow throughout the germinating period. The intact nonwoven fibrous structure of PCL fibers kept the roots from growing into the interconnected fiber web, which allows the growing seedlings to be easily transferred to the soil medium upon the completion of the germinating period. The germinating method of using electrospun fibers as initiated in this study was useful to easily observe the seed growth indoors on a soilless medium.

3.3. Fluid Uptake Ability (FUA). In this study, several important features of the electrospun fibers for the novel application in seed germination were considered, such as the fluid uptake ability (FUA) and the water vapor transmission rate (WVTR). Such properties are significant as the electrospun fibers were used as functional scaffolding material to support the process of seed growth. The FUA experimental data of 

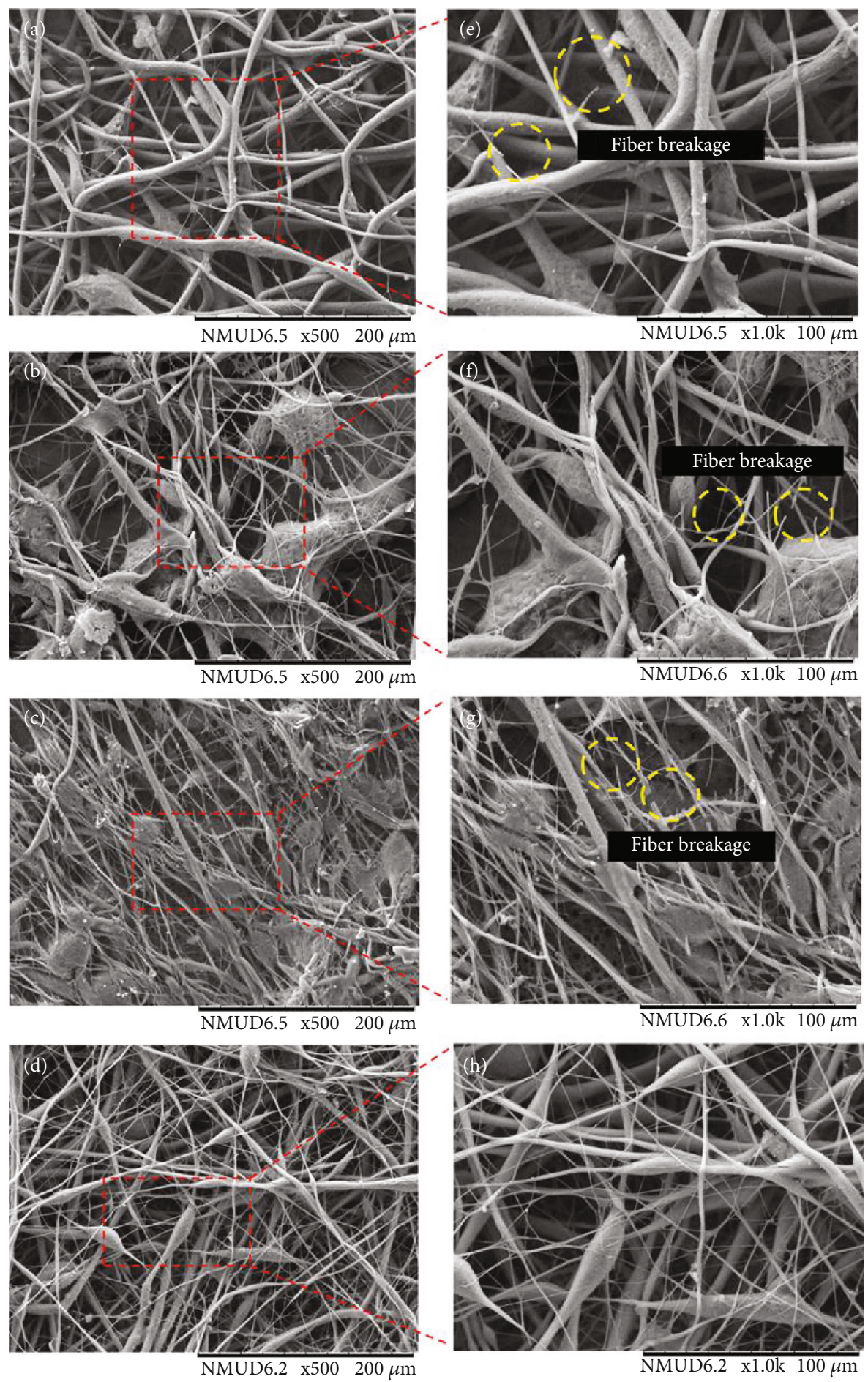

Figure 5: FESEM of spent electrospun PCL fibers at the flow rates of $0.05,0.10,0.15$, and $0.20 \mathrm{ml} / \mathrm{min}$ at a (a-d) magnification of 500x and (e-h) magnification of $1000 x$, respectively.

the electrospun fiber sample are given in Figure 6(a). The results were compared with those of laboratory grade cellulose wipes, denoted as $\mathrm{E}$ (diameter of the sample is $10 \mathrm{~mm}$ ). The result shows that all electrospun fibers have a higher percentage value of FUA than cellulose wipes. The large surface area of electrospun fibers and the presence of pores on the fibers favor fluid absorption as compared to cel- lulose wipes. On average, electrospun fibers can take approximately $19 \%$ more water than cellulose wipes per unit weight. Among the electrospun fiber samples, sample D has the highest FUA at $80.29 \pm 0.03 \%$, while sample $A$ has the lowest value of $76.33 \%$. It is proposed that sample $\mathrm{D}$ is the most suitable substrate for mung bean seed germination and appears to suggest that the electrospun fibers with a larger pores 

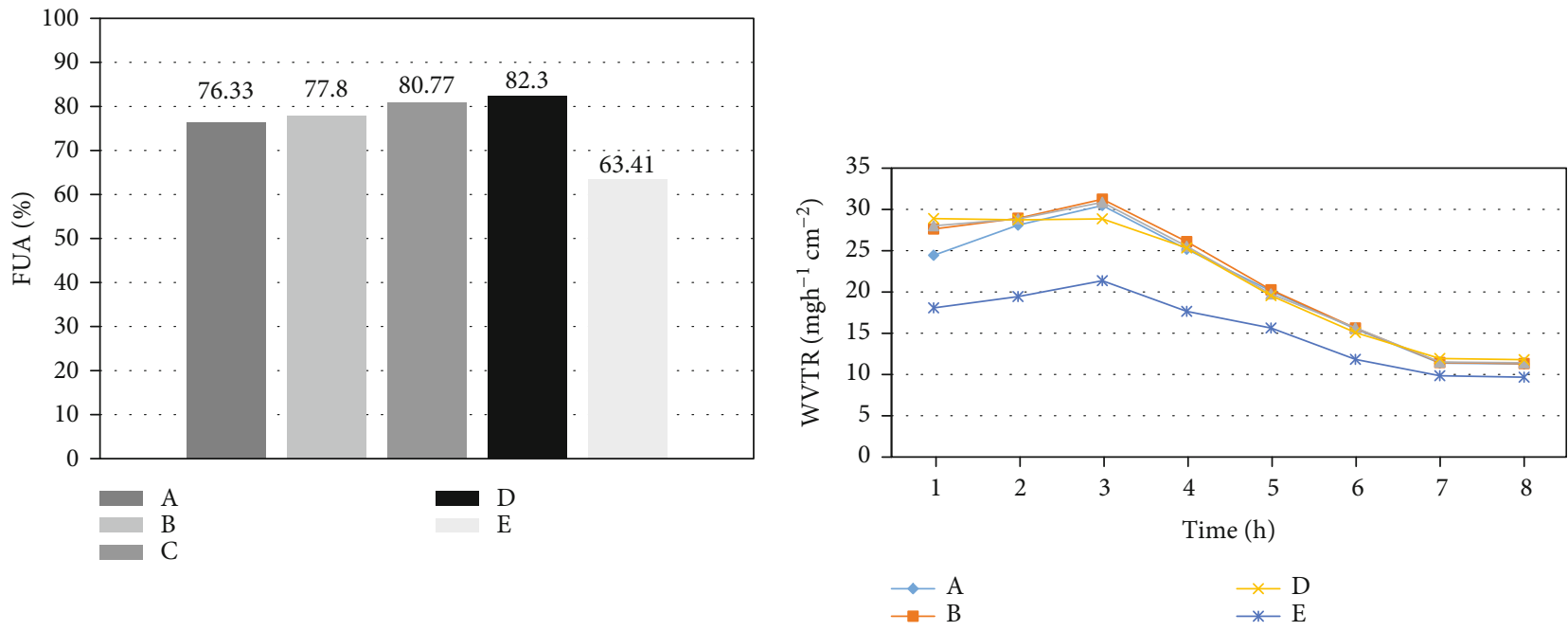

(a)

(b)

Figure 6: (a) The fluid uptake ability of the electrospun fibers (A-D) and cellulose wipe (E). (b) Changes of WVTR of electrospun fibers (AD) and cellulose wipe (E) versus time profiles.

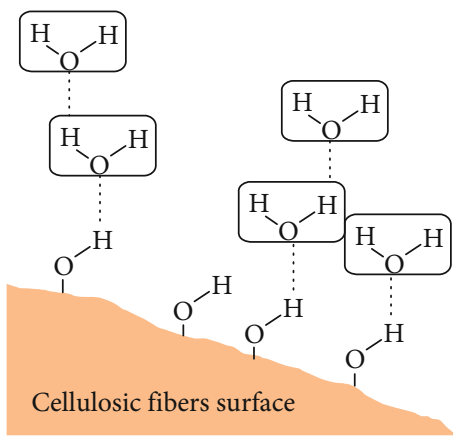

(a)

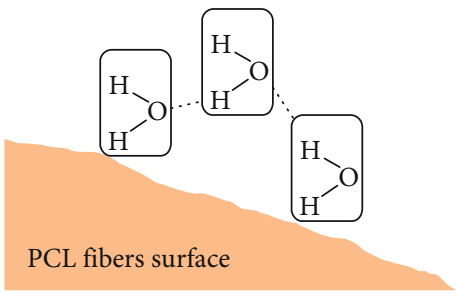

(b)

FIGURE 7: Illustration of (a) the hydrogen-bonding network of water to cellulose surface and (b) the hydrogen-bonding network of water to PCL fiber surface, respectively.

diameter will lead to a higher FUA. In addition, the fiber diameter may also affect the fluid uptake. Fibers with larger diameters have larger interfiber capillary radii, which will provide a higher FUA. The effects of pores and fiber diameter on fluid absorption and wettability have been reported elsewhere [42].

3.4. Water Vapor Transmission Rate (WVTR). The permeability rate indicates the condition where the applied water vapor is capable of moving through an electrospun fiber mat. In the case of excessive water loss via permeation through the electrospun fiber mat, the seed may get drowned or rot and this will retard the germinating process. Therefore, the electrospun fiber mat must be permeable to the moisture to an extent that there should neither be excessive loss of moisture to result in a dry surface nor should there be such a low permeability, which may cause the seeds to fail to germinate [43]. The WVTR of the electrospun fiber mats were determined at the RH of 50 percent, and the results of moisture gain versus time profiles are shown in Figure 6(b). The WVTR of electrospun fibers were found to be increased gradually for the first 3 hours and the moisture permeated rapidly. As more moisture replaced the air in the pores, the moisture permeated more slowly and eventually reached a steady state. In between 4 and 8 hours, the decrement in WVTR of electrospun fibers was observed, which may be attributed to high moisture content due to the filled interfacial gap. On the other hand, the WVTR of cellulose wipe was lower than that of the electrospun fibers due to the hydrogen bonding properties. It is reported that cellulose has a strong affinity toward itself and materials containing hydroxyls, especially water molecules due to its open structure containing hydroxyl $(\mathrm{OH})$ and acetyl $\left(\mathrm{C}_{2} \mathrm{H}_{3} \mathrm{O}\right)$ groups [44]. Based on the surface affinity to hydroxyl functional groups, cellulosic-based polymer is very reactive to water, due to the intermolecular hydrogen bonding interaction between water and the hydroxyl groups of the cellulose [45-47]. On the other hand, polycaprolactone (PCL) is a relatively hydrophobic type of polymer. The active group, which binds water molecules to the PCL surface, is ester bonds. Based on the thermodynamics study of water sorption in PCL reported by Scherillo et al., they conclude that a PCL film is exposed to water vapor at different 
relative pressures and temperatures. As a result, several types of hydrogen bond ( $\mathrm{HB}$ ) interactions have emerged, such as the HB link between sorbed water molecules (self-HB) and $\mathrm{HB}$ interactions between sorbed water molecules and proton acceptor groups on polymer backbone. The concentration of self-HB on a PCL surface shows an upward concavity, reflecting the assembling tendency of water molecules as water concentration increases [48]. The comparison of hydroxyl group interaction onto cellulose fiber and PCL fiber surfaces, respectively, is illustrated in Figure 7. Based on the results of WVTR, the ability to absorb and release moisture possessed by electrospun fiber mat has complied with the requirement to support seed germination. The permeability rate of electrospun fiber mat is higher compared to that of the cellulose wipe due to the difference in the chemical interaction involved with water molecules $[49,50]$.

\section{Conclusions}

This preliminary work demonstrates that the electrospun fibers are one of the substrate tolerant varieties for seed germination of mung beans. From the current study, it is concluded that electrospun PCL fibers support the early seedling growth of mung beans, owing to the properties of good fluid uptake ability and high surface area with interconnected pores of PCL fibers. The use of PCL fibers as a germinating medium has significantly increased the growth of radicle, plumule, and root length of mung bean seeds within 96 hours of the germinating period. The electrospun fiberbased materials have shown a considerable amount of success as the promising alternative to soilless medium for germinating seeds indoors. A very minimal structural fragmentation of smaller diameter electrospun fibers had occurred upon the seed germination period, which was due to the tension generated as a result of the water uptake by the seeds. By adjusting the electrospinning processing conditions, the electrospun fibers that are more uniform in diameter can be controlled to improve the structural integrity of electrospun fibers for future applications in seed germination. In addition, the assessment of appropriateness of the hypotheses adopted in this study shall be further testified by an examination in an aeration capacity, seed physiology quality, adverse environmental conditions, and susceptibility to fungi. To this aim, a valuable characterization from the FTIR spectroscopy, porosity, and surface area analysis would be an interesting continuation of this work.

\section{Data Availability}

The data used to support the findings of this study are included within the article.

\section{Conflicts of Interest}

The authors declare that there is no conflict of interest regarding the publication of this paper.

\section{Acknowledgments}

Immense gratitude is expressed by the authors to the Ministry of Higher Education, Malaysia, for providing research funding under the Fundamental Research Grant Scheme (Grant Project Number: FRGS/1/2019/STG07/UITM/03/2) and Faculty of Applied Sciences, Universiti Teknologi MARA (UiTM) Shah Alam, for providing research facilities and financial support.

\section{References}

[1] "Coronavirus pandemic has delivered the fastest, deepest economic shock in history," 2020, https://www.theguardian.com/ business/2020/mar/25/coronavirus-pandemic-has-deliveredthe-fastest-deepest-economic-shock-in-history.

[2] "Covid-19 and food security," 2020, https://www.csis.org/ programs/global-food-security-program/covid-19-and-foodsecurity.

[3] "The impact of COVID-19 on food security and nutrition," 2020, https:/www.tralac.org/documents/resources/covid-19/ 3813-the-impact-of-covid-19-on-food-security-andnutrition-un-policy-brief-june-2020/file.html.

[4] M. Hanif, M. K. Khattak, I. Ul Haq et al., "Effects of temperature and water purity on germination and yield of mungbean sprouts," Sains Malaysiana, vol. 48, no. 4, pp. 711-717, 2019.

[5] Z. Yi-Shen, S. Shuai, and R. FitzGerald, "Mung bean proteins and peptides: nutritional, functional and bioactive properties," Food \& Nutrition Research, vol. 62, pp. 1290-1300, 2018.

[6] D. Hou, L. Yousaf, Y. Xue et al., "Mung bean (Vigna radiata L.): bioactive polyphenols, polysaccharides, peptides, and health benefits," Nutrients, vol. 11, no. 6, pp. 1238-1265, 2019.

[7] K. Ganesan and B. Xu, "A critical review on phytochemical profile and health promoting effects of mung bean (Vigna radiata)," Food Science and Human Wellness, vol. 7, no. 1, pp. 11-33, 2018.

[8] B. HanumanthaRao, R. M. Nair, and H. Nayyar, "Salinity and high temperature tolerance in mungbean [Vigna radiata (L.) Wilczek] from a physiological perspective," Frontiers in Plant Science, vol. 7, pp. 957-976, 2016.

[9] M. Faisal, U. Ahmad, and D. Wulandani, "Determination of mung bean seed viability change in vacuum packaging during storage in different temperatures," IOP Conference Series: Materials Science and Engineering, vol. 557, no. 1, pp. 012074-012084, 2019.

[10] M. J. Islam, M. K. Hassan, S. R. Sarker, A. B. Rahman, and M. S. A. Fakir, "Light and temperature effects on sprout yield and its proximate composition and vitamin $\mathrm{C}$ content in Lignosus and mung beans," Journal of the Bangladesh Agricultural University, vol. 15, no. 2, pp. 248-254, 2017.

[11] S. Ramakrishna, K. Fujihara, W. E. Teo, T. C. Lim, and Z. Ma, Eds., "Basics Relevant to Electrospinning," in An Introduction to Electrospinning and Nanofibers, pp. 22-89, World Scientific Publishing Co. Pte. Ltd., 2005.

[12] D. H. Reneker, A. L. Yarin, E. Zussman, and H. Xu, "Electrospinning of nanofibers from polymer solutions and melts," in Advances in Applied Mechanics, pp. 43-346, Institute of Fundamental Technological Research, 2007.

[13] X. Qin and S. Subianto, "Electrospun nanofibers for filtration applications," in Electrospun Nanofibers, pp. 449-466, Woodhead Publishing, Cambridge, 2017. 
[14] F. Fadil, F. A. Adli, N. D. N. Affandi, A. M. Harun, and M. K. Alam, "Dope-dyeing of polyvinyl alcohol (PVA) nanofibres with Remazol Yellow FG," Polymers, vol. 12, no. 12, pp. 3043-3055, 2020.

[15] F. Fadil, N. D. N. Affandi, M. I. Misnon, N. N. Bonnia, A. M. Harun, and M. K. Alam, "Review on electrospun nanofiberapplied products," Polymers, vol. 13, no. 13, p. 2087, 2021.

[16] N. Reddy, R. Reddy, and Q. Jiang, "Crosslinking biopolymers for biomedical applications," Trends in Biotechnology, vol. 33, no. 6, pp. 362-369, 2015.

[17] M. K. Gaydhane, J. S. Kanuganti, and C. S. Sharma, "Honey and curcumin loaded multilayered polyvinylalcohol/cellulose acetate electrospun nanofibrous mat for wound healing," Journal of Materials Research, vol. 35, no. 6, pp. 600-609, 2020.

[18] S. Adepu, M. Gaydhane, C. Kakunuri, S. Sharma, M. Khandelwal, and S. J. Eichhorn, "Effect of micropatterning induced surface hydrophobicity on drug release from electrospun cellulose acetate nanofibers," Applied Surface Science, vol. 426, pp. 755-762, 2017.

[19] M. Zhang, X. Zhao, G. Zhang, G. Wei, and Z. Su, "Electrospinning design of functional nanostructures for biosensor applications," Journal of Materials Chemistry B, vol. 5, no. 9, pp. 1699-1711, 2017.

[20] V. Krishnamoorthy, G. Elumalai, and S. Rajiv, "Environment friendly synthesis of polyvinylpyrrolidone nanofibers and their potential use as seed coats," New Journal of Chemistry, vol. 40, no. 4, pp. 3268-3276, 2016.

[21] M. K. Gaydhane, S. P. Pudke, and C. S. Sharma, "Neem oil encapsulated electrospun polyurethane nanofibrous bags for seed storage: a step toward sustainable agriculture," Journal of Applied Polymer Science, vol. 138, no. 11, p. 50003, 2021.

[22] A. Cesari, M. V. Loureiro, M. Vale, E. I. Yslas, M. Dardanelli, and A. C. Marques, "Polycaprolactone microcapsules containing citric acid and naringin for plant growth and sustainable agriculture: physico-chemical properties and release behavior," Science of the Total Environment, vol. 703, article 135548, 2020.

[23] P. Milani, D. França, A. G. Balieiro, and R. Faez, "Polymers and its applications in agriculture," Polímeros, vol. 27, no. 3, pp. 256-266, 2017.

[24] P. D. S. C. Mariani, A. P. V. Neto, J. P. da Silva, E. J. B. N. Cardoso, E. Esposito, and L. H. Innocentini-Mei, "Mineralization of poly( $\varepsilon$-caprolactone)/adipate modified starch blend in agricultural soil," Journal of Polymers and the Environment, vol. 15, no. 1, pp. 19-24, 2007.

[25] A. Wang, C. Xu, C. Zhang, Y. Gan, and B. Wang, "Experimental investigation of the properties of electrospun nanofibers for potential medical application," Journal of Nanomaterials, vol. 2015, Article ID 418932, 8 pages, 2015.

[26] M. Bajpai, S. K. Bajpai, and D. Gautam, "Investigation of regenerated cellulose/poly(acrylic acid) composite films for potential wound healing applications: a preliminary study," Journal of Applied Chemistry, vol. 2014, Article ID 325627, 9 pages, 2014.

[27] X. L. Shen, J. M. Wu, Y. Chen, and G. Zhao, “Antimicrobial and physical properties of sweet potato starch films incorporated with potassium sorbate or chitosan," Food Hydrocolloids, vol. 24, no. 4, pp. 285-290, 2010.

[28] A. S. Ali and A. A. Elozeiri, "Metabolic processes during seed germination," in Advances in Seed Biology, pp. 141-166, IntechOpen, 2017.
[29] A. C. Miano, J. . C. Pereira, N. Castanha, M. D. . M. Júnior, and P. E. D. Augusto, "Enhancing mung bean hydration using the ultrasound technology: description of mechanisms and impact on its germination and main components," Scientific Reports, vol. 6, no. 1, pp. 38996-39009, 2016.

[30] X. Gómez-Maqueo and A. Gamboa-deBuen, "The dynamics of plant cell wall in muro modifications and its physiological implications on seed germination," in New Challenges in Seed Biology - Basic and Translational Research Driving Seed Technology, pp. 155-177, InTech, London, UK, 2016.

[31] M. Mo, K. Yokawa, Y. Wan, and F. Baluška, "Corrigendum: How and why do root apices sense light under the soil surface?," Frontiers in Plant Science, vol. 6, p. 775, 2015.

[32] M. Krawiec, A. Dziwulska-Hunek, S. Palonka, M. Kaplan, and P. Baryla, "Effect of laser irradiation on seed germination and root yield of scorzonera (Scorzonera hispanica L.)," Acta Agrophysica, vol. 23, pp. 621-631, 2016.

[33] R. V. B. Janayon and R. A. Guerrero, "Laser irradiation of mung bean (Vigna radiata L.) at two wavelengths for enhanced seedling development," International Journal of Optics, vol. 2019, Article ID 3479562, 7 pages, 2019.

[34] M. Akhalkatsi and R. Lösch, "Water limitation effect on seed development and germination in Trigonella coerulea (Fabaceae)," Flora, vol. 200, no. 6, pp. 493-501, 2005.

[35] N. A. Ibrahim, N. D. N. Affandi, and N. Samsulrizal, "The effects of intrinsic parameters on the formation of electrospun polycaprolactone fibre," International Journal of Engineering and Advanced Technology, vol. 9, pp. 5699-5704, 2019.

[36] N. D. N. Affandi, N. A. Ibrahim, and F. Fadil, “Tuning surface roughness of electrospun poly caprolactone fibres by single solvent electrospinning system," Digest Journal of Nanomaterials and Biostructures, vol. 15, pp. 1069-1074, 2020.

[37] C.-H. Park, E. K. Kim, L. D. Tijing et al., "Preparation and characterization of LA/PCL composite fibers containing beta tricalcium phosphate $(\beta$-TCP) particles," Ceramics International, vol. 40, no. 3, pp. 5049-5054, 2014.

[38] P. Kuppan, S. Sethuraman, and U. M. Krishnan, "PCL and PCLgelatin nanofibers as esophageal tissue scaffolds: optimization, characterization and cell-matrix interactions," Journal of Biomedical Nanotechnology, vol. 9, no. 9, pp. 1540-1555, 2013.

[39] A. H. Hekmati, N. Khenoussi, H. Nouali, J. Patarin, and J. Y. Drean, "Effect of nanofiber diameter on water absorption properties and pore size of polyamide- 6 electrospun nanoweb," Textile Research Journal, vol. 84, no. 19, pp. 20452055, 2014.

[40] I. Greenfeld and E. Zussman, "Polymer entanglement loss in extensional flow: evidence from electrospun short nanofibers," Journal of Polymer Science Part B: Polymer Physics, vol. 51, no. 18, pp. 1377-1391, 2013.

[41] M. Tsuge, K. Takahashi, R. Kurimoto et al., "Fabrication of water absorbing nanofiber meshes toward an efficient removal of excess water from kidney failure patients," Fibers, vol. 7, no. 5, pp. 39-47, 2019.

[42] Young Ah Kwon and A. Majid Sarmadi, "Wettability of nonwoven fabrics: effect of laundering on water absorption," Clothing and Textiles Research Journal, vol. 13, no. 1, pp. 1729, 1995.

[43] V. M. Vainburg, A. A. Lysenko, L. M. Shtyagina, E. L. Illarionova, T. I. Chufarovskaya, and N. I. Sverdlova, "Fibrous materials as artificial soil substrates," Fibre Chemistry, vol. 40, no. 4, pp. 308-313, 2008. 
[44] A. B. Maslinda, M. S. Abdul Majid, M. J. M. Ridzuan, and A. R. Syayuthi, "Water absorption behaviour of hybrid interwoven cellulosic fibre composites," Journal of Physics: Conference Series, vol. 908, p. 012015, 2017.

[45] A. Chami Khazraji and S. Robert, "Self-Assembly and Intermolecular Forces When Cellulose and Water Interact Using Molecular Modeling," Journal of Nanomaterials, vol. 2013, Article ID 745929, 12 pages, 2013.

[46] A. Chami Khazraji and S. Robert, "Interaction Effects between Cellulose and Water in Nanocrystalline and Amorphous Regions: A Novel Approach Using Molecular Modeling," Journal of Nanomaterials, vol. 2013, Article ID 409676, 10 pages, 2013.

[47] B. Lindman, B. Medronho, L. Alves, C. Costa, H. Edlund, and M. Norgren, "The relevance of structural features of cellulose and its interactions to dissolution, regeneration, gelation and plasticization phenomena," Physical Chemistry Chemical Physics, vol. 19, no. 35, pp. 23704-23718, 2017.

[48] G. Scherillo, L. Sanguigno, L. Sansone, E. Di Maio, M. Galizia, and G. Mensitieri, "Thermodynamics of water sorption in poly( $\varepsilon$-caprolactone): a comparative analysis of lattice fluid models including hydrogen bond contributions," Fluid Phase Equilibria, vol. 313, pp. 127-139, 2012.

[49] A. M. Bochek and L. M. Kalyuzhnaya, "Interaction of water with cellulose and cellulose acetates as influenced by the hydrogen bond system and hydrophilic-hydrophobic balance of the macromolecules," Russian Journal of Applied Chemistry, vol. 75, no. 6, pp. 989-993, 2002.

[50] V. Soukupova, L. Boguslavsky, and R. J. D. AnandJiwala, "Studies on the properties of biodegradable wipes made by the hydroentanglement bonding technique," Textile Research Journal, vol. 77, no. 5, pp. 301-311, 2007. 